\title{
Optimal graft diameter and location reduce postoperative complications after total arch replacement with long elephant trunk for arch aneurysm
}

\author{
Haruhiko Kondoh, MD, ${ }^{\mathrm{a}}$ Toshihiro Funatsu, MD, ${ }^{\mathrm{a}}$ Koich Toda, MD, ${ }^{\mathrm{b}}$ Satoshi Kainuma, MD, \\ Satoru Kuki, MD, ${ }^{\mathrm{c}}$ and Kazuhiro Taniguchi, $\mathrm{MD}^{\mathrm{a}}$
}

\begin{abstract}
Objective: Total arch replacement with an elephant trunk is a standard treatment for arch aneurysm, but serious complications, such as paraplegia and peripheral embolization caused by flapping of the elephant trunk, remain. Moreover, dilation of the descending aorta and retrograde flow into the peri-graft space at the distal elephant trunk are frequent problems. We hypothesized that optimal graft diameter and location would reduce complications after total arch replacement with a long elephant trunk by achieving complete thrombosis and minimal dilation of the descending aorta around the elephant trunk.
\end{abstract}

\begin{abstract}
Methods: We treated 65 patients with arch aneurysm by total arch replacement with a long elephant trunk anastomosed at the base of the innominate artery. The graft diameter was undersized $(10 \%-20 \%$ of the distal aorta's diameter). Elephant trunk length was determined by preoperative computed tomography to locate the distal end at Th6 to Th8. Thrombosis around the elephant trunk, diameter of the descending aorta, and distance between the descending aorta and the graft near the distal end of the elephant trunk were evaluated using computed tomography.
Results: The distal end of the elephant trunk was located at Th $8 \pm 1$. There were no operative deaths, 3 patients $(5 \%)$ died in the hospital, and 3 patients $(5 \%)$ experienced spinal cord injury, including 1 in whom permanent paraplegia developed. Computed tomography revealed complete thrombosis around the elephant trunk in 58 pa- tients $(89 \%)$. The descending aorta did not dilate further, and distance between the descending aorta and the graft progressively decreased.

Conclusions: Optimal graft diameter and location minimized postoperative complications, with complete thrombosis and no dilation of the descending aorta around the long elephant trunk in most patients. ( $\mathrm{J}$ Thorac Cardiovasc Surg 2011;142:319-25)

Since the original elephant trunk (ET) technique was developed by Borst and coworkers in $1983,{ }^{1}$ 2-stage surgery, with total arch replacement using an ET in the first stage, has been the preferred treatment for extensive ascending, arch, and descending aortic aneurysms. ${ }^{2,3}$ The procedure involves replacing the ascending aorta and the aortic arch with a prosthesis and extending the arch graft, the ET, to the descending aorta through a median sternotomy. ${ }^{1-3}$ In the second-stage procedure, the ET can be extended to the desired level thorough a lateral thoracotomy. ${ }^{1-3}$ However,

\footnotetext{
From the Department of Cardiovascular Surgery, ${ }^{\text {a }}$ Japan Labor Health and Welfare Organization, Osaka Rosai Hospital, Sakai, Osaka, Japan; Department of Cardio-

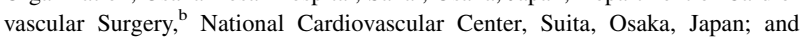
Department of Cardiovascular Surgery, ${ }^{\mathrm{c}}$ Takarazuka Municipal Hospital, Takarazuka, Hyogo, Japan.

Disclosures: Authors have nothing to disclose with regard to commercial support.

Received for publication April 14, 2010; revisions received Sept 5, 2010; accepted for publication Oct 16, 2010; available ahead of print April 4, 2011.

Address for reprints: Kazuhiro Taniguchi, MD, Department of Cardiovascular Surgery, Japan Labor Health and Welfare Organization, Osaka Rosai Hospital, Sakai, Japan, 1179-3, Nagasone-cho, Sakai 591-025, Japan (E-mail: kataniguchi-cvs@ orh.go.jp).

$0022-5223 / \$ 36.00$

Copyright (C) 2011 by The American Association for Thoracic Surgery

doi:10.1016/j.jtcvs.2010.10.035
}

further dilation of the descending aorta or rupture of the aneurysmal aorta may still occur if the retrograde flow from the distal end of the ET into the peri-graft space around it continues after the first-stage procedure, although this technique has been modified and improved by several groups. ${ }^{1,2,4-8}$ Moreover, serious complications, such as paraplegia and peripheral embolic complications caused by flapping of the ET, remain concerns after this procedure. ${ }^{9}$

Karck and associates ${ }^{10}$ introduced a novel combined surgical and interventional approach, the so-called frozen ET procedure, using an oversized stent graft $(10 \%-20 \%$ larger than the diameter of the descending aorta) to prevent retrograde flow into the aneurysm. This procedure permits the surgical treatment to be completed in a single operation through a median sternotomy. In their procedure, a prototype, hybrid prosthesis stent graft is placed in the descending aorta, antegrade to the aneurysm, through the opened aortic arch, and the ascending aorta and aortic arch are replaced conventionally. ${ }^{10}$ As a result, the retrograde flow can be prevented in almost all patients during the early postsurgical period. However, the continuous radial force of the rigid and oversized stent graft will force the descending aorta to dilate around the stent. This effect has led to several 


\section{Abbreviations and Acronyms \\ ANOVA $=$ analysis of variance \\ CT = computed tomography \\ ET $=$ elephant trunk}

cases of peri-graft endoleak or rupture of the descending aorta in the late postsurgical stage. ${ }^{11}$ These events indicate that choosing the appropriate size for the graft is critical, but this parameter has yet to be established. Furthermore, the fate of the descending aorta at the distal end of the ET remains unclear. Related to this, the location of the distal end of the ET is clearly important, because very long ETs are associated with increased risk of spinal cord injury, and very short ETs may promote retrograde flow into the aneurysm. ${ }^{12}$

We reported previously that our modification of the ET procedure, in which the ET anastomosis is placed in the ascending aorta at the base of the innominate artery, prevents injuries to both the recurrent laryngeal and phrenic nerves, and results in fewer complications related to intraoperative hemorrhage. ${ }^{13-15}$ Our procedure uses an undersized graft, with a diameter that is $10 \%$ to $20 \%$ less (range, $18-28$ $\mathrm{mm}$ ) than that of the descending aorta, and the graft length is chosen so that the distal end of the ET will be between the sixth and eighth thoracic vertebral level. The descending aortic diameter and required ET length are determined by preoperative computed tomography (CT) scans.

This study addressed the following specific questions about the graft's diameter and location: (1) Is the location of the end of the graft associated with increased risk of spinal cord injury or retrograde flow into the peri-graft space? (2) Would using an undersized graft (as described above) reduce postoperative peripheral embolic events and the incidence of paraplegia? (3) Would an undersized graft prevent retrograde flow and further dilation of the descending aorta around the ET?

\section{MATERIALS AND METHODS \\ Patients}

Between July 1999 and March 2009, 85 patients with arch aneurysms underwent total arch replacement with a long ET. Among them, 65 consecutive patients whose thoracic descending aorta was less than $40 \mathrm{~mm}$ in diameter at the sixth to eighth thoracic vertebral level were enrolled in this study after approval was obtained from the institutional review board and informed consent was provided by each patient. The baseline patient clinical characteristics, including associated comorbidities, are shown in Table 1 . Ten patients had significant coronary artery disease, requiring a preoperative percutaneous coronary intervention in 4 and concomitant coronary artery bypass grafting in 6 . Seven patients required aortic valve replacement, 6 patients required aortic root replacement with a composite graft, and 1 patient required concomitant aortic valve and mitral valve replacement. Sixteen patients received postoperative warfarin therapy after
TABLE 1. Preoperative patient characteristics

\begin{tabular}{lc}
\hline Age $(\mathrm{y})$ & $70 \pm 9($ range, $45-85)$ \\
Men/women & $47(72 \%) / 18(28 \%)$ \\
Cerebral infarction & $11(17 \%)$ \\
Coronary artery disease & $10(15 \%)$ \\
Valvular disease & $15(23 \%)$ \\
Abdominal aortic aneurysm & $9(14 \%)$ \\
\hline
\end{tabular}

cardiac valvular surgery or atrial fibrillation, and 10 patients received postoperative antiplatelet therapy for coronary arterial bypass grafting or percutaneous coronary intervention.

\section{Surgical Procedures}

The surgical technique used in this study, total arch replacement with a long ET anastomosed at the base of innominate artery, was reported previously. ${ }^{15}$ Briefly, the ascending aorta and arch vessels were minimally dissected using a median sternotomy. Then, 8-mm Dacron grafts (Gelweave, Vascutek, Germany) were anastomosed to the right and left axillary arteries below the clavicle. The patient was started on cardiopulmonary bypass with arterial return through an 8-mm Dacron graft anastomosed to the right axillary artery and venous drainage from the bicaval cannula, and then cooled to $25^{\circ} \mathrm{C}$.

While the patient was cooled, the heart was arrested by antegrade and retrograde cold blood cardioplegia, after which a 4-branched arch graft (Hemashield Platinum, MAQUET Cardiovascular LLC, Wayne, NJ) was sutured into the sinotubular junction (Figure 1,A). The diameter of the ET was based on the outer diameter of the descending aorta at the Th6 to Th8 vertebral level determined from preoperative CT scans, and was $10 \%$ to $20 \%$ smaller (range, $18-28 \mathrm{~mm}$ ), to obtain an adequate contact zone between the ET and the aortic wall at the end of the ET. When the patient had been cooled to $25^{\circ} \mathrm{C}$, systemic perfusion was stopped, and then both the proximal left subclavian and proximal left common carotid arteries were closed with clips or sutures, and the innominate artery was clamped. Selective cerebral perfusion was then instituted using the 8-mm Dacron grafts anastomosed to the right and left axillary arteries, with an additional 3-mm small cannula in the left common carotid artery. The ascending aorta was transected at the base of the innominate artery, and the long ET was placed into the aortic arch and descending aorta by pulling the ET with a catching catheter (Amplatz Goose-Neck Snare; Microvena, White Bear Lake, Minn) introduced from the femoral artery (Figure 1, B). For each patient, the length of the ET was determined preoperatively by measuring the lesser curvature of the aorta from the base of the innominate artery to the descending aorta at the sixth and eighth thoracic vertebral levels, and 3-0 Tevdek sutures (Akiyama Medical Manufacturing Co, Ltd, Tokyo, Japan) were placed on the lesser curvature of the ET to fix its length and prevent stretching (Figure 1, B). A distal anastomosis was then performed at the base of the innominate artery between the 4-branched arch graft and the long ET tube graft, incorporating the distal ascending aorta (Figure 1, C). Before completing the distal anastomosis, the 4-branched arch graft was clamped between the first and second branches, and the dislodged intimal debris was washed out from the long ET by perfusing the descending aorta via a small arterial cannula placed in the right femoral artery. After antegrade distal perfusion was resumed from the side branch of the graft, the patient was rewarmed. During rewarming, the innominate artery and left common carotid artery were divided and anastomosed to the branches of the graft, and the most distal branch was anastomosed to the left axillary artery graft, which was introduced into the pericardial space through a retroclavicular tunnel (Figure 1,D).

\section{Follow-up and Measurements}

All patients underwent a CT scan within both 1 week and 1 month after surgical intervention. Those patients who demonstrated complete 

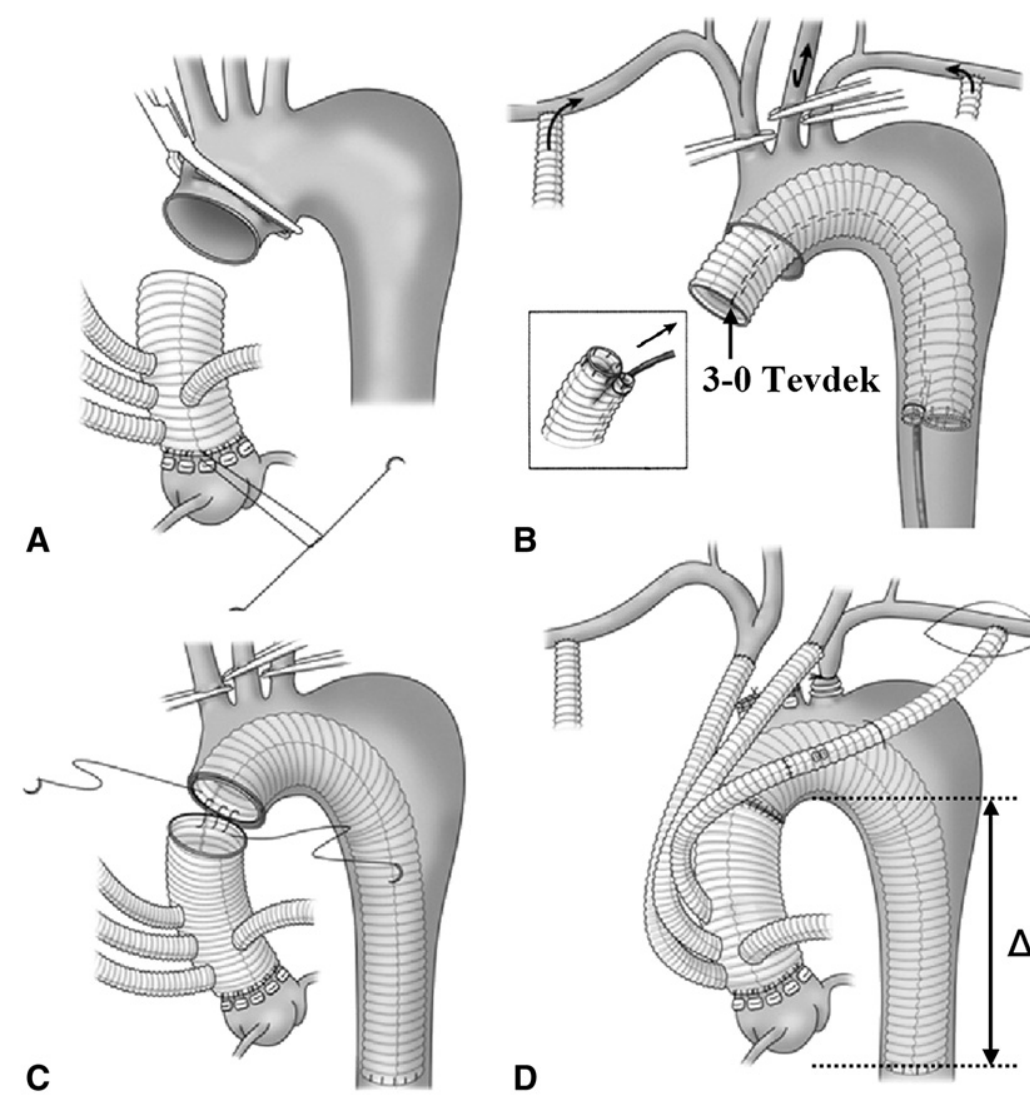

B

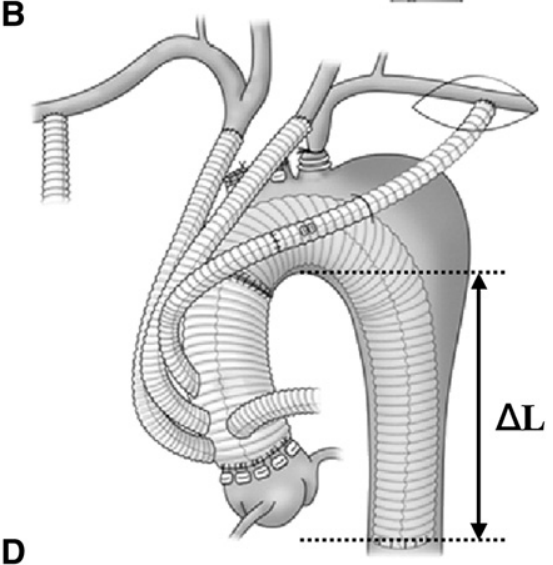

FIGURE 1. Total arch replacement with a long ET anastomosed at the base of the innominate artery. A, Four-branched arch graft is sutured into the sinotubular junction under cardioplegic arrest. B, After systemic perfusion is switched to selective cerebral perfusion using the right and left axillary arteries, and a small cannula is placed in the left common carotid artery, the distal ascending aorta is transected, and the long ET is placed into the aortic arch by pulling the ET with a catching catheter. C, Distal anastomosis is performed between the 4-branched arch graft and the long ET graft incorporating the distal ascending aorta. D, After antegrade distal perfusion is resumed from the side branch of the graft, the patient is rewarmed and the arch vessels are reconstructed. $\Delta L$, Length from the origin of the descending aorta at the lesser curvature of the aortic arch to the distal end of the ET.

thrombosis of the arch aneurysm on the CT scan were discharged and followed on an outpatient basis, during which serial CT scans were performed annually thereafter. The remaining patients, who did not demonstrate complete thrombosis of the aneurysm on CT scans, required a second-stage procedure, which has been described. ${ }^{13}$ Briefly, the descending aorta was exposed through an anterolateral left thoracotomy, the descending aorta was clamped during normothermic femoro-femoral veno-arterial bypass, the long ET was pulled out, and the distal end was anastomosed to the descending aorta.

Measurements were obtained from all the available postoperative CT scans, and the distal end of the ET was defined on the image as coinciding with the complete clip set (ie, where the metal clips were actually implanted). The diameter of the descending aorta at $2 \mathrm{~cm}$ above and $2 \mathrm{~cm}$ below the distal end of the ET and the difference in the diameters of the descending aorta and the ET $(\Delta \mathrm{D})$ at 1,2 , and $3 \mathrm{~cm}$ above the distal end of the ET were measured. The diameter of the descending aorta was defined as its shortest external diameter, and $\Delta \mathrm{D}$ was calculated by subtracting the diameter of the descending aorta from the external diameter of the graft. Analysis was confined to 2-dimensional transverse images. To perform the measurements, the images were scanned at 300 dots per inch and measured with a computerized planimeter (National Institutes of Health Image, Bethesda, Md). The aortic images were enlarged, and the diameters were measured and calculated by using the accompanying calibration scales. The vertical length from the origin of the descending aorta at the lesser cur- vature of the aortic arch to the distal end of the graft $(\Delta \mathrm{L})$ was measured using the sagittal plane of the postoperative $\mathrm{CT}$ angiogram by 2 radiologists (Figure 1, D).

\section{Statistical Analysis}

All values, except the $\Delta \mathrm{D}$, were expressed as the mean \pm standard deviation and subjected to multiple analysis of variance (ANOVA) using SPSS Version 11.0 (SPSS Inc, Chicago, IIl). The $\Delta \mathrm{D}$ was expressed as the mean \pm standard error of the mean. The diameter of the descending aorta and the $\Delta \mathrm{D}$ were first analyzed by 1-way repeated-measures ANOVA for differences across the whole time course, and 1-way ANOVA with the Tukey-Kramer post hoc test was used to verify the significance for specific comparisons at each time point. A chi-square test was used for the comparison of frequencies between 2 groups. Other numeric data were analyzed by the Mann-Whitney $U$ test.

\section{RESULTS}

\section{Operative Outcome}

None of the patients died intraoperatively or within 30 days of the operation, although 3 patients $(5 \%)$ died while in the hospital. Of these, 1 patient with chronic renal failure died of mediastinitis 3 months after the operation, 1 patient 
died of pneumonia, and 1 patient died of a graft infection. None of the patients had a new stroke, peripheral embolic events, new onset of retrograde flow into the peri-graft space, rupture, recurrent nerve palsy, or phrenic nerve palsy, whereas 1 patient $(2 \%)$ had permanent paraplegia due to a Th6 level spinal cord injury, 1 patient $(2 \%)$ had paraparesis from a Th1 to Th4 level spinal cord injury, and 1 patient $(2 \%)$ had transient paraplegia. The distal end of the ET was located at the Th10 level in 2 of these patients and at the Th8 level in 1 patient. In the follow-up period, 7 patients died after discharge, but none of them died of rupture or reexpansion of the aneurysm (Table 2).

\section{Complete Thrombosis of the Peri-Graft Space Around the Long Elephant Trunk}

CT scans demonstrated complete thrombosis of the perigraft space around the long ET in 58 patients $(89 \%)$ within 1 month after the operation, but not in the remaining 7 patients $(11 \%)$. Six of these 7 patients underwent a subsequent distal anastomosis in the descending aorta through a left thoracotomy, and the remaining patient, an 85-year-old woman with acute aortic dissection, is being followed up. The characteristics of patients with and without complete thrombosis of the peri-graft space around the long ET are compared in Table 3. The size of the descending aorta, selected graft size, and location of the end of the graft were similar in both groups. However, the maximum size of the aneurysm was significantly larger in the nonthrombosed group than in the completely thrombosed group. Moreover, even the 25 patients in the completely thrombosed group who were given long-term warfarin therapy (after cardiac valvular surgery or atrial fibrillation in 15 [26\%] and as antiplatelet therapy for coronary arterial bypass grafting or percutaneous coronary intervention in $10[17 \%]$ ) showed complete thrombosis of the peri-graft space around the long ET without new onset of peri-graft perfusion for at least 4 years after the operation.

\section{Diameter of the Descending Aorta and $\Delta \mathrm{D}$ at the Distal End of the Elephant Trunk}

Table 4 shows the diameter of the descending aorta at the distal end of the ET up to 4 years after surgery. No dilation of the diameter of the descending aorta at any measurement

TABLE 2. Late deaths after discharge and cause of death

\begin{tabular}{lcclc}
\hline Patient & Age, $\mathbf{y}$ & Gender & \multicolumn{1}{c}{ Cause of death } & Survival mo \\
\hline 1 & 69 & M & Cerebellar hemorrhage & 11 \\
2 & 82 & M & Congestive heart failure & 12 \\
3 & 75 & M & Pneumonia & 12 \\
4 & 70 & M & Pneumonia & 14 \\
5 & 70 & M & Sepsis & 14 \\
6 & 73 & M & Unknown & 38 \\
7 & 74 & M & Iliac aneurysm rupture & 61 \\
\hline
\end{tabular}

TABLE 3. Comparison of patient characteristics in terms of the extent of thrombosis in the peri-graft space at the distal elephant truck

\begin{tabular}{|c|c|c|c|}
\hline & $\begin{array}{c}\text { Completely } \\
\text { thrombosed } \\
\text { group }(n=58)\end{array}$ & $\begin{array}{l}\text { Nonthrombosed } \\
\text { group }(n=7)\end{array}$ & $\begin{array}{c}P \\
\text { value }\end{array}$ \\
\hline Age (y) & $69 \pm 9$ & $76 \pm 5$ & .00249 \\
\hline Men/women & $41(71 \%) / 17$ & $6(86 \%) / 1(14 \%)$ & .6629 \\
\hline Dissection & $14(24 \%)$ & $1(14 \%)$ & .9070 \\
\hline $\begin{array}{l}\text { Abdominal aorta } \\
\text { graft replace }\end{array}$ & $7(12 \%)$ & $2(29 \%)$ & .2471 \\
\hline $\begin{array}{l}\text { Size of descending } \\
\text { aorta }(\mathrm{mm})\end{array}$ & $29.5 \pm 4.2$ & $33 \pm 2.4$ & .0683 \\
\hline Selected graft size $(\mathrm{mm})$ & $24 \pm 2$ & $25 \pm 2$ & .2417 \\
\hline Size of aneurysm $(\mathrm{mm})$ & $54.2 \pm 8.0$ & $70.0 \pm 16.4$ & .0023 \\
\hline End of the graft (Th) & $8 \pm 1$ & $7 \pm 2$ & .1852 \\
\hline$\Delta \mathrm{L}(\mathrm{cm})$ & $8.4 \pm 3.5$ & $4.8 \pm 2.1$ & .0183 \\
\hline \multicolumn{4}{|l|}{ Concomitant procedures } \\
\hline AVR & $7(12 \%)$ & 0 & .7357 \\
\hline $\begin{array}{l}\text { Composite valve } \\
\text { graft replacement }\end{array}$ & $6(10 \%)$ & 0 & .8316 \\
\hline $\mathrm{AVR}+\mathrm{MVR}$ & $1(2 \%)$ & 0 & .9999 \\
\hline CABG & $5(9 \%)$ & 0 & .9447 \\
\hline $\mathrm{CABG}+\mathrm{AVR}$ & $1(2 \%)$ & 0 & .9999 \\
\hline $\begin{array}{l}\text { Postoperative warfarin } \\
\text { therapy }\end{array}$ & $15(26 \%)$ & $1(14 \%)$ & .8303 \\
\hline $\begin{array}{l}\text { Postoperative antiplatelet } \\
\text { therapy }\end{array}$ & $10(17 \%)$ & $0(0 \%)$ & .5836 \\
\hline \multicolumn{4}{|c|}{$\begin{array}{l}E T \text {, Elephant trunk; } \Delta L \text {, the length from the end of the graft to the origin of the de- } \\
\text { scending aorta at the lesser curvature of the aortic arch; } A V R \text {, aortic valve replace- } \\
\text { ment; } M V R \text {, mitral valve replacement; } C A B G \text {, coronary artery bypass grafting. } \\
\text { Completely thrombosed group: patients with complete thrombosis of the peri-graft } \\
\text { space around the ET. Nonthrombosed group: patients without complete thrombosis } \\
\text { of the peri-graft space around the ET. }\end{array}$} \\
\hline
\end{tabular}

point was seen during this time frame. In contrast, the $\Delta \mathrm{D}$ did not reach significance, but gradually and progressively decreased in size (Table 4).

\section{Location of the Distal End of the Elephant Trunk}

The distal end of the ET was at the Th8 \pm 1 level, and the $\Delta \mathrm{L}$ was $8 \pm 4 \mathrm{~cm}$. In the 3 patients $(5 \%)$ with some degree of spinal cord injury, both the Th level and $\Delta \mathrm{L}$ were significantly greater than in the other 62 patients (Figure 2). However, in the 7 patients $(11 \%)$ in whom peri-graft perfusion developed, the correlation with Th level did not reach significance in comparison with the Th levels of the 58 patients without peri-graft perfusion (Figure 2). However, in all 7 patients with peri-graft perfusion, the $\Delta \mathrm{L}$ was less than $8 \mathrm{~cm}$, which was significantly shorter than that of the other patients.

\section{DISCUSSION}

The present study demonstrated that the use of an undersized graft (ie, a diameter $10 \%-20 \%$ smaller than that of the descending aorta) resulted in no dilation of the descending aorta at the ET and led to complete thrombosis between 
TABLE 4. Diameter of the descending aorta and $\triangle \mathrm{D}$ at the distal end of the elephant truck

\begin{tabular}{|c|c|c|c|c|c|c|c|}
\hline \multirow[b]{3}{*}{ No. of patients } & \multicolumn{7}{|c|}{ Time after the operation } \\
\hline & $1 \mathrm{wk}$ & $1 \mathrm{mo}$ & $1 \mathbf{y}$ & $2 y$ & $3 \mathbf{y}$ & $4 y$ & \\
\hline & 58 & 57 & 43 & 31 & 22 & 14 & $P$ value \\
\hline \multicolumn{8}{|c|}{ Diameter of descending aorta } \\
\hline $2 \mathrm{~cm}$ above $(\mathrm{mm})$ & $30.9 \pm 4.9$ & $29.0 \pm 4.6$ & $30.0 \pm 5.0$ & $29.2 \pm 4.4$ & $30.4 \pm 5.5$ & $29.5 \pm 4.3$ & .4917 \\
\hline Distal end $(\mathrm{mm})$ & $29.5 \pm 4.2$ & $28.4 \pm 4.3$ & $28.9 \pm 3.9$ & $28.2 \pm 3.0$ & $28.8 \pm 4.1$ & $28.4 \pm 3.6$ & .7379 \\
\hline $2 \mathrm{~cm}$ below $(\mathrm{mm})$ & $29.7 \pm 3.9$ & $28.2 \pm 3.8$ & $28.6 \pm 3.6$ & $28.0 \pm 3.1$ & $28.0 \pm 2.9$ & $28.5 \pm 3.2$ & .2887 \\
\hline \multicolumn{8}{|l|}{$\Delta \mathrm{D}(\mathrm{mm})$} \\
\hline $3 \mathrm{~cm}$ above $(\mathrm{mm})$ & $7.8 \pm 0.7$ & $6.5 \pm 0.8$ & $6.5 \pm 0.8$ & $5.7 \pm 0.7$ & $5.6 \pm 1.2$ & $5.2 \pm$ & .2392 \\
\hline $2 \mathrm{~cm}$ above $(\mathrm{mm})$ & $7.5 \pm 0.6$ & $6.3 \pm 0.7$ & $6.3 \pm 0.8$ & $5.6 \pm 0.8$ & $5.6 \pm 1.0$ & $4.4 \pm 1.1$ & .2145 \\
\hline $1 \mathrm{~cm}$ above $(\mathrm{mm})$ & $6.9 \pm 0.6$ & $6.0 \pm 0.8$ & $5.9 \pm 0.8$ & $5.1 \pm 0.8$ & $5.1 \pm 0.9$ & $4.2 \pm 1.1$ & .3202 \\
\hline Distal end $(\mathrm{mm})$ & $6.0 \pm 0.6$ & $5.6 \pm 0.8$ & $5.2 \pm 0.7$ & $4.7 \pm 0.7$ & $4.2 \pm 0.9$ & $3.3 \pm 0.9$ & .1395 \\
\hline
\end{tabular}

the ET and the descending aorta in most patients for at least 4 years after total arch replacement. Moreover, there were no postoperative peripheral embolic complications, new onsets of peri-graft perfusion, or aortic ruptures. Most patients did not require a second-stage operation. These findings suggest that the use of an optimal graft diameter may minimize postoperative complications.

The optimal graft size for the ET has been unclear, although various modifications have been reported since the operation was first described. ${ }^{1,2,6-8}$ Generally, a 26- to $30-\mathrm{mm}$ diameter graft is used, and the distal anastomosis is usually performed just distal to the left subclavian artery, with the aneurysmal aorta being tailored down to the selected graft size if necessary. ${ }^{4}$ However, when retrograde flow from the distal end of the ET into the perigraft space around it continues after the surgery, further dilation of the descending aorta or rupture of the aneurysmal aorta may occur. ${ }^{4,5,16}$ Moreover, the flapping action

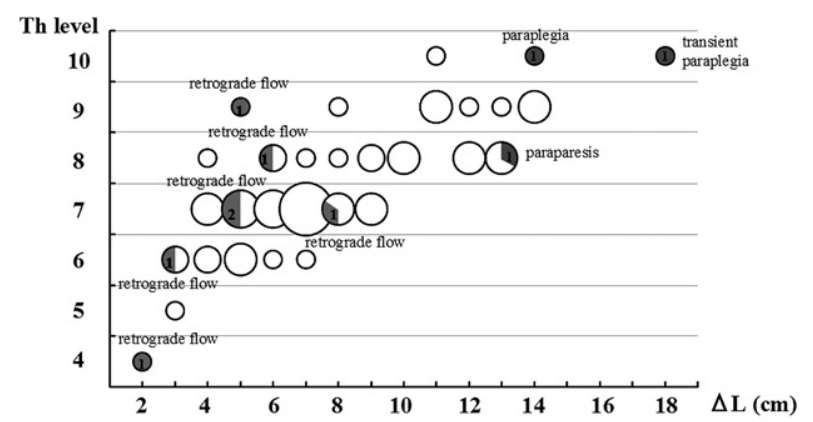

\begin{tabular}{|c|c|c|c||c|c|c|c|}
\hline & $\begin{array}{c}\text { retrograde } \\
\text { flow }(+) \\
(\mathrm{n}=7)\end{array}$ & $\begin{array}{c}\text { retrograde } \\
\text { flow }(-) \\
(\mathrm{n}=58)\end{array}$ & & $\begin{array}{c}\text { Spinal cord injury } \\
(+) \\
(\mathrm{n}=3)\end{array}$ & $\begin{array}{c}\text { Spinal cord injury } \\
(-) \\
(\mathrm{n}=62)\end{array}$ & \\
\hline Th & $6.9 \pm 1.6$ & $7.5 \pm 1.2$ & $\mathrm{P}=0.1852$ \\
\hline$\Delta \mathrm{L}(\mathrm{cm})$ & $4.8 \pm 2.1$ & $\mathbf{8 . 4} \pm 3.5$ & $\mathbf{P = 0 . 0 1 8 3}$ \\
\hline
\end{tabular}

FIGURE 2. Relationship between complications (spinal cord injury and retrograde flow into the peri-graft space) and the location of the end of the ET (the Th level and $\Delta \mathrm{L}$ ). The size of each circle represents the number of patients. Solid red and blue represent complications, as indicated. Long grafts were associated with an increased risk of spinal cord injury, and short grafts were associated with retrograde flow. $\Delta \mathrm{L}$ varied, even when the distal end of the graft was positioned at the same thoracic vertebral level. of the free part of the graft may cause postsurgical peripheral embolic events by dislodging the clot that forms around the graft. ${ }^{9}$ Therefore, the graft size should be selected so that the distal end of the ET is tightly positioned in the descending aorta to prevent retrograde flow into the peri-graft space and flapping of the graft.

In our procedure, we not only chose an undersized graft but also tightened the graft in its position in the aortic arch and descending aorta by pulling it with a catching catheter introduced from the left femoral artery. In addition, to reduce the risk of intraoperative embolic events, we washed out the dislodged intimal debris from the long ET by perfusing the descending aorta via a small arterial cannula placed in the right femoral artery, before completing the distal anastomosis. Our procedure was effective in addressing the known risks of peri-surgical complications in most patients. The descending aorta around the ET was not dilated in any patient for at least 4 years after the surgery. Most patients showed complete thrombosis between the graft and the descending aorta. Finally, there were no postsurgical peripheral embolic events.

In our series, 7 patients (nonthrombosed group) did not show complete thrombosis between the graft and descending aorta postoperatively, and the thoracic vertebral level of the distal end of the ET was similar in both the completely thrombosed and nonthrombosed groups. In contrast, the distance from the end of the graft to the origin of the descending aorta at the lesser curvature of the aortic $\operatorname{arch}(\Delta \mathrm{L})$ in the nonthrombosed group was significantly shorter than in the completely thrombosed group. In addition, the maximum diameter of the aneurysm in the nonthrombosed group was significantly larger than in the completely thrombosed group. Therefore, our results suggest that, even if the distal end of the graft is positioned at the optimal thoracic vertebral level, peri-graft perfusion may still occur when the maximum diameter of the aneurysm is larger than 70 $\mathrm{mm}$ and the $\Delta \mathrm{L}$ is short.

Karck and coworkers ${ }^{10,17}$ introduced the so-called frozen ET technique, using a hybrid procedure in which a prosthetic stent graft is placed into the descending aorta to prevent 
retrograde flow into the aneurysm. They showed that retrograde flow was prevented in 20 patients $(91 \%)$ by using 30- to 46-mm stent grafts, and in the few patients with residual retrograde flow, an additional endgraft placed into the stent graft through the femoral artery resolved the problem. ${ }^{10,18}$ However, in the frozen ET procedure, the stent graft is intentionally oversized by $10 \%$ to $20 \%$ of the descending aortic diameter, so that the radial force from the stent keeps it in place, and the stent graft is molded to the aortic wall with the help of an appropriately sized balloon catheter after its deployment. ${ }^{18}$ The result is continuous force on the aorta at the position of the stent graft, leading to its dilation. The likely clinical relevance of this problem was confirmed when several cases of new onset of endoleak or rupture of the descending aorta some time after the frozen ET procedure were reported, ${ }^{11}$ although the precise mechanism and incidence of endoleak or rupture after the frozen ET procedure are not yet certain.

In contrast, our procedure uses a soft and undersized woven graft, and although retrograde flow occurred in 7 patients $(11 \%)$ in the early postsurgical phase, in the other 58 patients $(89 \%)$ retrograde flow was successfully prevented without dilation of the descending aorta at the ET for at least 4 years. Moreover, the $\Delta \mathrm{D}$ gradually became smaller with time. Thus, the undersized graft seems likely to continue to prevent retrograde flow into the aneurysm for a long time. Although the precise mechanism for the complete thrombosis of the peri-graft space after our procedure is not yet certain, we propose 3 possible causes for it. First, the distal end of the ET is fitted to the aortic wall; under this condition, there is little blood flow (peri-graft perfusion) through the narrow space between the ET and aortic wall, which might lead to gradual thrombus formation. Second, the outer wall of the ET produced thrombi on its surface, which might have become attached to the aortic inner surface. Third, the peri-graft space around the ET became a blind end, and the flow of the intercostal arteries was gradually reduced and finally stopped, which might lead to the formation of complete thrombosis of the perigraft space after the procedure.

The location of the distal end of the ET can affect the risk of spinal cord injury and retrograde flow. ${ }^{12}$ Our results confirmed this finding, showing that the $\Delta \mathrm{L}$ varied, even when the distal end of the ET was positioned at the same thoracic vertebral level. Therefore, if the $\Delta \mathrm{L}$ is very large, the distal end of the ET should not be placed beyond the Th8 level to reduce the risk of spinal cord injury, even if retrograde flow cannot be prevented. The use of intraoperative transesophageal echocardiography to confirm the distal end of the ET has been reported..$^{15}$ The use of this technique could prevent the placement of the ET beyond the level of Th8, thereby preventing the occlusion of the critical intercostal arteries, which are mostly located at the Th9-L2 level, by an excessively long ET.
In our procedure, 58 patients $(89 \%)$ did not seem to require a second-stage operation, because the peri-graft space around the ET was completely thrombosed. Among our 65 patients with a first \pm second-stage operation, there were 3 deaths and 3 cases of spinal cord injury (4.6\%). Karck and Kamiya ${ }^{19}$ recently reported an extensive review of the clinical data for a variety of procedures used to treat arch aneurysm. In this review, the summarized rate of paraplegia after the frozen ET procedure, as a single-stage procedure, was $4.2 \%$, almost the same rate we observed, and the rate of mortality and risk of new onset of endoleak were both $7 \% .{ }^{19}$ On the other hand, for patients undergoing the 2 -stage procedure (ET procedure + subsequent operation), the summarized rate of mortality was $8.9 \%$ (70/786 patients) for the first-stage operation and 7.7\% (20/268 patients) for the second-stage operation, which are higher than our result $(4.6 \%$ in the first \pm second-stage operation). ${ }^{19}$ It is difficult to compare the rate of paraplegia with these reports, because many of the reported patients did not return for the second-stage operation, so the patient outcome data are incomplete. Moreover, Safi and colleagues ${ }^{20}$ recently reported that the interval mortality (occurring after the first-stage and before the secondstage operation) was $16 \%$ in their series. Endovascular treatment recently was applied for the second-stage operation, and among these cases, mortality was $4.9 \%(2 / 41$ patients) and none of the patients experienced paraplegia. ${ }^{19}$ Although the results of this procedure seem promising, the cohort was relatively small. Thus, our procedure is safe and decreases the need for a second-stage operation, compared with various other procedures used to treat arch aneurysm.

\section{CONCLUSIONS}

Although the optimal location of the distal end of the ET remains to be confirmed, our study supports the effectiveness of using an undersized graft $(10 \%-20 \%$ of the descending aortic diameter) with a long ET in total arch replacement to treat aneurysm.

\section{References}

1. Borst HG, Walterbusch G, Schaps D. Extensive aortic replacement using "elephant trunk" prosthesis. Thorac Cardiovasc Surg. 1983;31:37-40.

2. Borst HG, Frank G, Schaps D. Treatment of extensive aortic aneurysms by a new multiple-stage approach. J Thorac Cardiovasc Surg. 1988;95:11-3.

3. Heinemann MK, Buehner B, Jurmann MJ, Borst HG. Use of the "elephant trunk technique" in aortic surgery. Ann Thorac Surg. 1995;60:2-7.

4. Carrel T, Berdat P, Kipfer B, Eckstein F, Schmidli J. The reversed and bidirectional elephant trunk technique in the treatment of complex aortic aneurysms. J Thorac Cardiovasc Surg. 2001;122:587-91.

5. Estrera AL, Miller CC III, Porat EE, Huynh TT, Winnerkvist A, Safi HJ. Staged repair of extensive aortic aneurysms. Ann Thorac Surg. 2002;74: S1803-32.

6. Svensson LG. Rationale and technique for replacement of the ascending aorta, arch, and distal aorta using a modified elephant trunk procedure. J Card Surg. 1992;7:301-12.

7. Mori Y, Hirose H, Takagi H, Umeda Y, Fukumoto Y, Shimabukuro K, et al. Aortic arch repair for Stanford type A aortic dissection with distal anastomosis to the 
proximal level of the distal aortic arch. J Thorac Cardiovasc Surg. 2003;126: 415-9.

8. Kusuhara K, Shiraishi S, Iwakura A. A new staged operation for extensive aortic aneurysm by means of the modified "elephant trunk" technique. J Thorac Cardiovasc Surg. 1995;110:267-9.

9. Crawford ES, Coselli JS, Svensson LG, Safi HJ, Hess KR. Diffuse aneurysmal disease (chronic aortic dissection, Marfan, and mega aorta syndromes) and multiple aneurysm. Treatment by subtotal and total aortic replacement emphasizing the elephant trunk operation. Ann Surg. 1990;211:521-37.

10. Karck M, Chavan A, Hagl C, Friedrich H, Galanski M, Haverich A. The frozen elephant trunk technique: a new treatment for thoracic aortic aneurysms. $J$ Thorac Cardiovasc Surg. 2003;125:1550-3.

11. Toyama M, Usui A, Yoshikawa M, Ueda Y. Thoracic aneurysm rupture due to graft perforation after endovascular stent-grafting via median sternotomy. Eur J Cardiothorac Surg. 2005;27:162-4.

12. Flores J, Kunihara T, Shiiya N, Yoshimoto K, Matsuzaki K, Yasuda K. Extensive deployment of the stented elephant trunk is associated with an increased risk of spinal cord injury. J Thorac Cardiovasc Surg. 2006;131:336-42.

13. Kuki S, Taniguchi K, Masai T, Yokota T, Yoshida K, Yamamoto K, et al. An alternative approach using long elephant trunk for extensive aortic aneurysm: elephant trunk anastomosis at the base of the innominate artery. Circulation. 2002; 106:I253-8.
14. Taniguchi K, Toda K, Hata H, Shudo Y, Matsue H, Takahashi T, et al. Elephant trunk anastomosis proximal to origin of innominate artery in total arch replacement. Ann Thorac Surg. 2007;84:1729-34.

15. Toda K, Taniguchi K, Hata H, Shudo Y, Matsue H, Kuki S, et al. Single-stage repair of arch aneurysms with a long elephant trunk: medium-term follow-up of thromboexcluded aneurysms. J Thorac Cardiovasc Surg. 2007;134:47-52.

16. Kouchoukos NT, Masetti P, Rokkas CK, Murphy SF. Single-stage reoperative repair of chronic type A aortic dissection by means of the arch-first technique. $J$ Thorac Cardiovasc Surg. 2001;122:578-82.

17. Karck M, Chavan A, Khaladj N, Friedrich H, Hagl C, Haverich A. The frozen elephant trunk technique for the treatment of extensive thoracic aortic aneurysms: operative results and follow-up. Eur J Cardiothorac Surg. 2005;28: 286-90.

18. Baraki H, Hagl C, Khaladj N, Kallenbach K, Weidemann J, Haverich A, et al. The frozen elephant trunk technique for treatment of thoracic aortic aneurysms. Ann Thorac Surg. 2007;83:S819-31.

19. Karck M, Kamiya H. Progress of the treatment for extended aortic aneurysms; is the frozen elephant trunk technique the next standard in the treatment of complex aortic disease including the arch? Eur J Cardiothorac Surg. 2009;33:1007-13.

20. Safi HJ, Miller CC III, Estrera AL, Villa MA, Goodrick JS, Porat E, et al. Optimization of aortic arch replacement: two-stage approach. Ann Thorac Surg. 2007;83:S815-8 